\title{
The end of the atmospheric xenon Archean's evolution: a study of the Great Oxygenation Event period
}

\author{
LISA MARIE ARDOIN ${ }^{1}$, MICHAEL BROADLEY ${ }^{2}$, \\ MATTHIEU ALMAYRAC ${ }^{3}$, DAVID BYRNE ${ }^{4}$, GUILLAUME \\ AVICE $^{5}$ AND BERNARD MARTY ${ }^{6}$ \\ ${ }^{1} \mathrm{CRPG}$ - Université de Lorraine \\ ${ }^{2} \mathrm{CRPG}$ \\ ${ }^{3}$ CRPG Université de Lorraine \\ ${ }^{4}$ Centre de Recherches Pétrographiques et Géochimiques \\ ${ }^{5} \mathrm{CNRS}$ IPGP/UMR 7154 \\ ${ }^{6}$ Université de Lorraine \\ Presenting Author: lisa.ardoin@univ-lorraine.fr
}

Several geochemical tracers (S, C, O, Xe) underwent irreversible global changes during the Precambrian, and in particular during the Great Oxygenation Event (GOE), between the Archean and Proterozoïc eons [1].

Xenon is of particular interest as it presents a secular isotopic evolution during the Archean that ceased around the time of the GOE. In this regard $\mathrm{Xe}$ is somewhat analogous to massindependent fractionation sulfur (MIF-S) in that it can be used to categorically identify Archean atmospheric components [2]. Xe isotopes in the modern atmosphere are strongly mass-dependent fractionated (MDF-Xe), with a depletion of the light isotopes relative to the heavy ones. There was a continuous Xe isotope evolution from primitive Xe to modern Xe that ceased between 2.6 and $1.8 \mathrm{Ga}$ [2] and this evolution has been attributed to coupled $\mathrm{H}^{+}-\mathrm{Xe}^{+}$escape to space [3].

The purpose of this project is to document the noble gas composition of paleoatmospheric noble gases trapped in welldated hydrothermal quartz fluid inclusions with ages covering the Archean-Proterozoic transition.

Our preliminary results from $2441 \pm 1.6$ Ma hydrothermal quartz veins from the Seidocherka sedimentary formation (Imandra-Varzuga Greenstone belt, Russia) indicate that Xe isotopes are marginally fractionated in favour of the light isotopes by $2.06 \pm 1.80(2 \sigma) \% \mathrm{u}^{-1}$ relative to the modern atmosphere. However, younger pods quartz from the Ongeluk formation (Kaapvaal Craton, South Africa) which formed at $2423 \pm 3 \mathrm{Ma}$ is similar to modern Xe $\left(0.6 \pm 2.1(2 \sigma) \%\right.$. $\left.\mathrm{u}^{-1}\right)$. Thus, the fractionation process appears to have stopped between the formation of these two samples, which is shortly after the final appearance of MIF-S in the geological record $(2.45 \mathrm{Ga})$. For Xe, massive escape of $\mathrm{H}^{+}$advocated to lift $\mathrm{Xe}^{+}$through the atmospheric column might have ended up due to oxidation.

[1] Catling \& Zahnle, 2020, Sciences Advances 6, eaax1420. [2] Avice et al., 2018, Geochimica et Cosmochimica Acta 232, 82-100 [3] Zahnle et al., 2019, Geochimica et Cosmochimica Acta 244, 56-85. 